\title{
Recuperation of chicken litter in preparation for extrusion
}

\author{
Sergey Ignatiev*, Aleksey Khrameshin, Roman Khrameshin, and Andrey Myakishev \\ Izhevsk State Agricultural Academy, 426069 Izhevsk, Russia
}

\begin{abstract}
In the article we proposed a technological solution aimed at solving the current problems of poultry enterprises and specifically at the disposal of litter. The technology of processing litter into fertilizer was analyzed. It is proposed to combine the processes of sorption drying, high-temperature extrusion and vacuum drying in the production of the dry granulated fertilizer from litter. Studies of the sorption capacity of dried litter have shown that its moisture and granulometric properties do not affect the pattern of moisture transfer between the litter and the sorbent material.
\end{abstract}

\section{Introduction}

One of the current problems of poultry enterprises is the disposal of litter [1]. Often poultry manure is accumulated near poultry farms in plots where it is kept for a certain time in order to ensure the composting process and then transported to the fields and scattered followed by cultivation into the soil.

When using the described technology environmental pollution is not excluded and during transportation over a distance of more than $10 \mathrm{~km}$ the cost of applying such fertilizer to the soil does not compensate by adding yield.

Modern technologies of the preparation of organic fertilizers for soil application give granulated products. The use of organic fertilizers in granulated form reduces transportation costs, facilitates the application of organic matter into the soil, simplifies the calculation of the dosage.

One of the ways of obtaining granules with the simultaneous disinfection of manure is high-temperature extrusion. It is carried out by the displacement of the material through the hole at high pressure. Due to excessive moisture in the litter this treatment is not possible.

To solve this problem it is proposed to perform dewatering of the incoming material for processing due to the previously treated litter having a low humidity that is due to its recuperation.

The aim of the study is studying the process of reducing the moisture content of the litter before its granulation by high-temperature extrusion with recuperation.

Research tasks are to:

- explore various technologies for the treatment and disposal of litter;

- justify the need of litter recuperation;

- explore the sorption capacity of dried litter.

\section{Analysis of the state of the issue}

There are biological and physical methods in the utilization and processing of manure [2, 3]. The biological method is carried out by composting, anaerobic fermentation, processing using vermiculture and larvae of flies. The physical method is carried out by mechanical dehydration, drying (thermal, vacuum) and granulation.

Composting is carried out in piles with a height of $2 \ldots 4 \mathrm{~m}$, in which organic substances gradually decompose under the influence of aerobic microorganisms.

Anaerobic fermentation is carried out in a digester without air, in which a certain temperature and humidity of the substrate is maintained. As a result of the activity of anaerobic microorganisms, not only fertilizer can be obtained but also biogas [4].

Vermicomposting is based on the processing of manure using the California worm [5].

Growing on the organic substrate of the larvae of flies allows you to receive biohumus from the litter.

Mechanical dehydration is carried out by pressing or centrifuging. Vacuum can be used to intensify drying and preserve useful elements in organic fertilizer.

Thermal drying of bird manure in drying plants makes it convenient for transportation, long-term storage. Heat treatment of the litter destroys pathogenic microorganisms and brings it to almost sterile purity. However at present time many poultry farms are not able to use this energy-intensive method.

Vacuum drying of manure can be used in the production of dry manure coming from cellular batteries. The cost of obtaining dry litter will be less when the humidity of the litter mass will be low. It should be noted that the production of vacuum dryers is based on a continuous, environmentally safe single-stage drying process that allows processing of litter in a mode of

\footnotetext{
* Corresponding author:: ignatevsp@mail.ru
} 
gentle temperatures while preserving useful elements in organic fertilizer.

Sorption drying is one of the methods of processing poultry manure which involves reducing the moisture of the original product by adding a sorbent with lower humidity.

Granulating of manure granules is formed by the dry or wet method with drying [6].

In the matrix granulators with a wet method of obtaining granules the dosed supply is carried out, the mixture is grabbed in the gap of the matrix and roller, it is compressed in a narrowing space, the material is pushed along the matrix channel divided into separate granules.

Extrusion, with the dry method of obtaining granules, includes several processes: temperature treatment under pressure up to 40 atmospheres, mechanochemical deformation and "explosion" of the product when the granules are out from the extruder matrix. Achieving the desired moisture content for the implementation of hightemperature extrusion is possible by pre-drying or mixing with a filler having a lower humidity.

A comparative analysis of the technologies of the treatment and disposal of litter showed that the processing efficiency is maximum at high-temperature extrusion and drying. The blind side of the dry method of obtaining granules from litter by extrusion is that the implementation of chemical conversion and thermal disinfection is impossible without reducing the moisture content of the raw material.

An interesting solution was proposed in the patent of an extruder with a vacuum chamber [7]. In the proposed device, the feedstock is sent to the screw part of the extruder. The product captured by the auger passes through the pressing and dosing zones of the machine and then leads out through the die plate into the vacuum chamber. In the conditions of rapid transition of the extrudate from the area of high pressures to conditions of reduced pressure a decompression explosion occurs: the water in the product passes into the vapor state.

The disadvantage of the proposed method for granulation is that the process is not possible without reducing the moisture content of the original product to $30 \%$.

To solve this problem at the initial stage of manure processing it is proposed to mix the feedstock with a sorbent material. Straw, peat or waste wood can be used during the launch of the line. During the period of steady-state operation of the line, we carry out the recuperation of the litter that is use a part of the dry litter at the exit from the production line, granulated manure which is not implemented on time or dust-like particles caught by the air purification systems as a sorbent. The block diagram of the proposed method of processing litter is presented in Figure 1.

The use of the proposed technology for producing granulated manure gives safe fertilizer [8], reduces the load on the warehouses of intermediate storage of granular fertilizer in the offseason, increases the economic attractiveness of chicken manure processing technology [9], eliminates the dependence of poultry farms on external suppliers of straw, peat, wood waste and other sorbing materials.

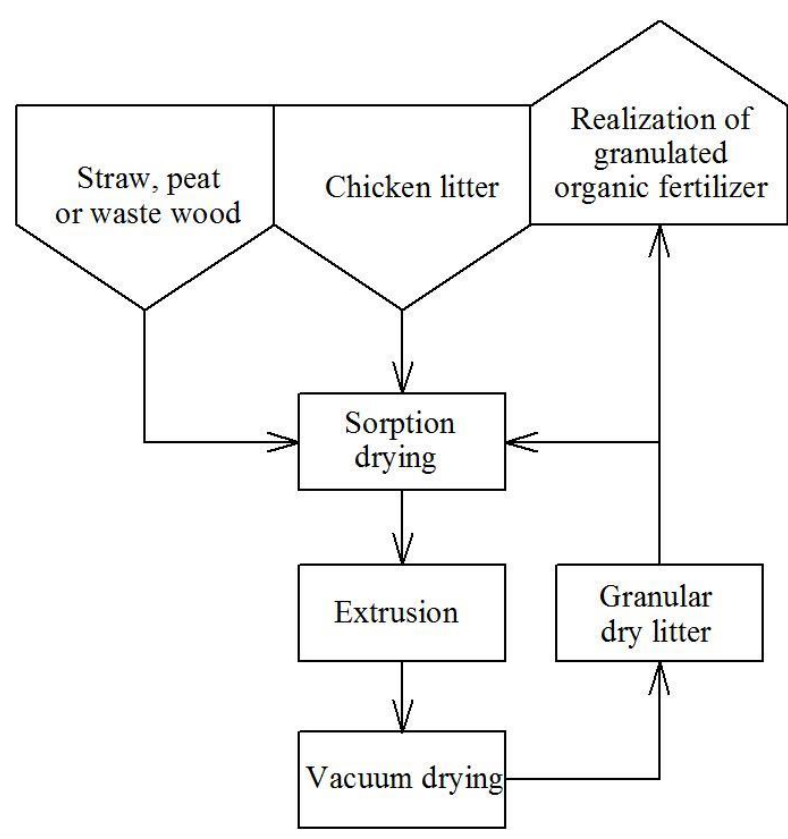

Fig. 1. Block diagram of technological solutions

Determination of the moisture content of the mixture during sorption drying is determined by the step-by-step method.

Initial moisture mass $\mathrm{m}_{\mathrm{w}_{\mathrm{n}}}$ in each of the mixed components is determined by the formula:

$$
m_{w_{n}}=m_{n \times w_{n}},
$$

where $m_{n}$ is the mass of the $n$-component, $\mathrm{kg} ; w_{n}$ is the humidity of the $n$-component, $\%$.

The total mass of moisture in the mixture is determined by the formula:

$$
\sum m_{w}=m_{w 1}+m_{w 2}
$$

The total mass of the mixture is determined by the formula:

$$
m_{\text {mix }}=m_{1}+m_{2} \text {, }
$$

where $m_{1}$ and $m_{2}$ are the initial masses of the components.

The moisture content of the mixture is determined by the formula:

$$
W=100 \sum m_{w} / m_{\text {mix }} .
$$

The given mathematical apparatus describes linear dependencies. In the course of the research, it is planned to confirm the assumption that the moisture and granulometric composition of the mixed components during sorption drying will not affect its mechanism.

\section{Research methods}

The object of the study is chicken manure. The subject of research is the ability of dry manure to absorb water 
from wet manure, regardless of moisture and granulometric properties.

When carrying out the research on the sorption capacity of dried litter, we use scales VLT-150P, moisture meter Sartorius MA30, stop watch, porcelain cup and containers for the samples under study. The initial sample is chicken manure that passes to the manure storehouse.

As a sorbent we used granulated chicken fertilizer FLOREKS-N, chicken manure of minimum achievable moisture and manure with humidity which corresponds to the characteristics of fertilizer FLOREKS-N. The investigated samples differ in moisture and granulometric composition.

To obtain the components of the minimum achievable humidity at the initial stage atmospheric drying is carried out. Further drying of the litter was carried out at temperature of $100{ }^{\circ} \mathrm{C}$ until reaching constant weight.

The drying temperature of the components when determining their moisture content with a Sartorius MA30 moisture meter at the initial stage of the study is set at $130{ }^{\circ} \mathrm{C}$. At the same time there is a decrease in the mass of the samples studied not only due to the evaporation of water but also due to thermal decomposition of the feather which is an integral part of chicken manure. In this regard, during the measurement of the moisture content of the mixture, the drying temperature is set as $100^{\circ} \mathrm{C}$.

When moisture is measured with a Sartorius MA30 moisture meter the required temperature is maintained, the heating mode is selected to heating to constant weight, the fertilizer is weighed, the lid is closed and after pressing the ENTER button the moisture meter automatically calculates the moisture of the litter during drying to constant weight according to the specified modes. The accuracy of the device in determining the humidity is $0.01 \%$.

According to GOST 26713-85 the allowable difference between the results of two parallel determinations of moisture content at a confidence coefficient of $\mathrm{P}=0.95$ should not exceed $0.3 \%$ for components with moisture content up to $30 \%$. When the moisture content of the components is $30 \ldots 70 \%$ the allowable difference between the results of parallel determinations should not exceed $1.0 \%$ [10]. The final value of humidity is determined by the average calculation of the results of five experiments.

When conducting studies of the sorption capacity of the dried litter the initial litter and the sorbent are mixed in ratios of $1: 4 ; 2: 3 ; 3: 2$ and $4: 1$. The error in the dosage of the components when using scales VLT-150P was 10$6 \mathrm{~kg}$. The components are mixed in a porcelain cup by pestle. Subsequently samples of the initial litter and sorbent before measuring moisture are in sealed packages.

The moisture content of the samples is determined at fivefold repetition of measurements using a Sartorius MA30 moisture meter using the method of drying moisture at a temperature of $100{ }^{\circ} \mathrm{C}$. The moisture meter automatically calculates the moisture of the litter when dried to constant weight.

\section{Results and discussions}

The results of determining the moisture content of the sorption drying are presented in table 1 .

Table 1. The humidity of the components of the sorption drying.

\begin{tabular}{|c|c|c|}
\hline Component name & $\begin{array}{c}\text { The average } \\
\text { value of } \\
\text { humidity, \% }\end{array}$ & $\begin{array}{c}\text { Standard } \\
\text { deviation of } \\
\text { the indicator }\end{array}$ \\
\hline $\begin{array}{c}\text { Litter on admission } \\
\text { to the storage room }\end{array}$ & 61.63 & 0.334 \\
\hline $\begin{array}{c}\text { FLOREKS-N } \\
\text { Granular Fertilizer }\end{array}$ & 13.92 & 0.212 \\
\hline $\begin{array}{c}\text { Litter minimum } \\
\text { achievable } \\
\text { moisture }\end{array}$ & 5.47 & 0.053 \\
\hline
\end{tabular}

The results of studies of litter entering the disposal are comparable to the values obtained at the South Ural State Agrarian University [11]. The actual moisture content of the granulated fertilizer FLOREKS-N according to the research results is higher than it is stated on the packaging by the fertilizer manufacturer.

The results of studies of the sorption capacity of dried manure when mixing wet chicken manure and sorbent in ratios of $1: 4 ; 2: 3 ; 3: 2$ and $4: 1$ are presented in table 2.

Table 2. The average humidity of the mixture during sorption drying, $\%$.

\begin{tabular}{|c|c|c|c|c|}
\hline $\begin{array}{c}\text { The name of the } \\
\text { component } \\
\text { sorbent } \\
\text { substances }\end{array}$ & \multicolumn{4}{|c|}{$\begin{array}{c}\text { The content of the sorbent in the } \\
\text { mixture of components, \% }\end{array}$} \\
\cline { 2 - 5 } & $\mathbf{2 0}$ & $\mathbf{4 0}$ & $\mathbf{6 0}$ & $\mathbf{8 0}$ \\
\hline $\begin{array}{c}\text { FLOREKS-N } \\
\text { granulated } \\
\text { fertilizer }\end{array}$ & 51.88 & 43.24 & 33.57 & 23.22 \\
\hline $\begin{array}{c}\text { Manure dried to } \\
\text { moisture of } \\
\text { fertilizer } \\
\text { FLOREKS-N }\end{array}$ & 51.06 & 41.84 & 33,57 & 23.17 \\
\hline $\begin{array}{c}\text { litter minimum } \\
\text { achievable } \\
\text { moisture }\end{array}$ & 48.58 & 38.00 & 25.88 & 13.5 \\
\hline
\end{tabular}

Graphic dependences of changes in the moisture content of the studied mixture on the percentage ratio of the sorbent in the mixture of components and their trend lines are presented in Figure 2.

The analysis of the graphs of Figure 2 confirms the linear characteristic between the parameters under study and indicates that the granulometric composition of the sorbent material with intensive mixing of the components does not affect the moisture transfer process. 


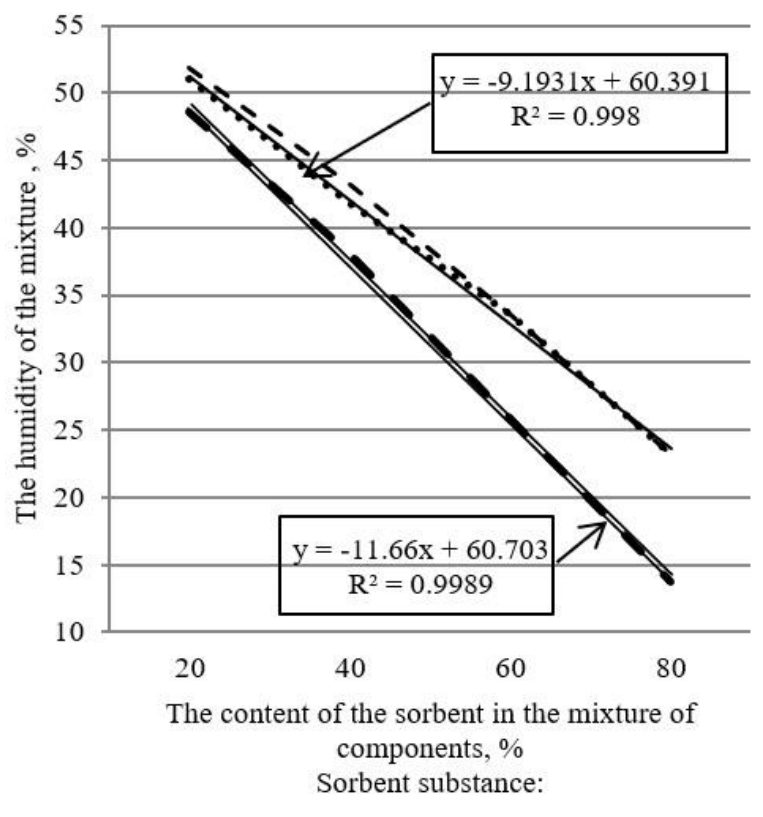

\section{- - - FLOREKS-N granulated fertilizer}

..... Manure dried to moisture of fertilizer FLOREKS-N

- - litter minimum achievable moisture

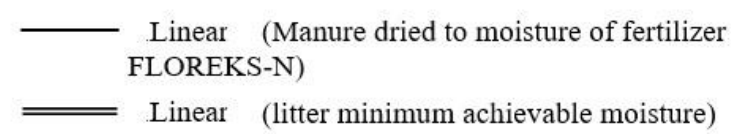

Fig. 2. Graphic displays of the study sorption drying litter

Based on the trend line formulas shown in Figure 2 the relationship between the final moisture content of a wet manure mixture with a sorbent and their initial moisture content of the sorbent in the mixture of components is obtained:

$$
W=\omega_{l}-\left(\omega_{l}-\omega_{s}\right) \frac{\gamma}{100}
$$

$W$ - moisture content of wet litter with sorbent, $\% ; \omega_{l}-$ litter humidity, $\% ; \omega_{s}-$ sorbent moisture, $\% ; \gamma-$ the content of the sorbent in the mixture of components, $\%$.

The dependence obtained allows us to calculate the moisture content of a mixture of litter with a sorbent with lower labor costs than using the methodology described in the section "Analysis of the state of the issue"

The substitution in formula (5) of the values from table 1 and the comparison of the calculated results with the experimental values obtained indicates that moisture transfer from the wet material to the sorbent is carried out according to a rule that does not depend on the initial moisture content of the sorbent material.

Thus, we confirmed the assumption that the moisture and granulometric composition of the mixed components during sorption drying will not affect its mechanism.

\section{Conclusion}

The research materials in the article indicate that the recuperation of the litter makes it possible to obtain the moisture content of the raw materials required for hightemperature extrusion. At the same time a more rational congestion of finished goods warehouses is ensured and the external dependence of poultry farms on suppliers of sorbent materials is eliminated.

In the study of the sorption capacity of dried litter it was established that its moisture and granulometric properties do not affect the pattern of moisture transfer between the litter and the sorbent material.

Further research should be directed to the study of the relationship between the moisture content of the litter mixture with the sorbent and its rheological properties, which affect the thermal disinfection of the litter in the proposed technology. The resulting dependence makes it possible to justify the effect of the sorbent on the rheological properties of the mixture under extrusion treatment and allows you to automate the process of feeding components into the plant to obtain granulated fertilizer from chicken manure.

\section{References}

1. O.V. Zakharchenko, Assessment of waste formation and prospects of implementing environmentally friendly wasteless technologies in livestock industry Scientific bulletin of Polesje 3-2(11), 82-88 (2017)

2. A.I. Piskaeva, Analysis of methods of processing agricultural organic waste on the example of chicken manure Economics: Economics and Agriculture 4(12), 2 (2016)

3. V.E. Sukhoperkova, Methods of utilization of bird droppings presented in modern patents Bulletin of the Altai State Agrarian University 9(143), 45-55 (2016)

4. S.P. Ignatiev, A.G. Larionova, Organic waste - a source of additional fuel AutoGas Refueling Complex + Alternative Fuel 5(47), 30-33 (2009)

5. V.V. Kasatkin et al., Justification of the technological scheme of the line processing manure into fertilizer Bulletin of Izhevsk State Agricultural Academy 2(23), 70-73 (2010)

6. T.N. Il'ina, E.I. Gibelev, Granulation in technology for utilization of industrial waste materials Chemical and Petroleum Engineering 45 7-8, 495499 (2009)

7. R.V. Shabnov et al., RU Patent 2561934 IPC: A23P1 / 12; B29C47 / 38 Extruder with a vacuum chamber № 2014125348/13, announced on 06.23.2014

8. D.V. Guryanov et al., Study of the temperature regime in the manufacture of granulated fertilizer from litter manure Bulletin of Michurinsky State Agrarian University 1, 140-143 (2018)

9. V.I. Marchenko et al., Investigation of the process of wet granulation of the solid fraction of fermented 
bird manure in Proc. of the Gorsky State Agrarian University 4, 180-187 (2018)

10. GOST 26713-85 Organic fertilizers. Method for determination of moisture and dry residue - Int.
1985-12-19 (Standards Publishing House, Moscow, 1986)

11. M.V. Zapevalov, A.M. Berdyshev, S.M. Zapevalov, Dehydration of bird manure before its processing Agrarian Bulletin of the Urals 1(107), 43-44 (2013) 